\title{
Animales, teorías feministas posmodernas y prácticas artísticas
}

\author{
Mireia Ferrer Álvarez \\ Universidad de Valencia \\ Mireia.ferrer@uv.es
}

RESUMEN: Este artículo pretende mostrar cómo algunas teorías feministas posmodernas como el Ecofeminismo y el Posthumanismo, de autoras como Françoise d'Eaubonne, Alicia Puleo, Donna Haraway o Rosi Braidotti han contribuido a la crítica contra las prácticas androcéntricas basadas en el dominio sistémico de devastación y explotación del otro/a/os, perpetuando la jerarquía y autoridad del hombre. Frente a ello estas autoras han propuesto un nuevo modelo de relación orgánica y de convivencia entre cultura y naturaleza, capaz de superar los modelos binarios, inspirado en el respeto a la diversidad de sexos y especies.

Estos principios se hallan, así mismo, en las prácticas artísticas de algunas autoras como Bonnie Ora Sherk, Fina Miralles, Olga Diego o María Llopis. Prácticas que transitan por la Performance, la Instalación o el Movimiento Auténtico.

PALABRAS CLAVE: Ecofeminismo; Posthumanismo; Arte Contemporáneo; Arte feminista; Land Art; Performance; Movimiento Auténtico.

\section{Animals, Postmodern Feminist Theories and Artistic Practices}

ABSTRACT: This article aims to show how some postmodern feminist theories such as Ecofeminism and Posthumanism, by authors like Françoise d'Eaubonne, Alicia Puleo, Donna Haraway or Rosi Braidotti have contributed to the criticism against androcentric practices based on the systemic dominion of devastation and exploitation of otherness, perpetuating the hierarchy and authority of the male. In contrast to this, these authors have proposed a new model of organic relationship and coexistence between culture and nature, capable of overcoming binary models, inspired by respect for the diversity of sexes and species.

These principles are found, likewise, in the artistic practices of some authors such as Bonnie Ora Sherk, Flna Miralles, María Llopis or Olga Diego. Practices that move through Performance, Installation or Authentic Movement.

KEYWORDS: Ecofeminism; Posthumanism; Contemporary Art; Feminist Art; Land Art; Performance; Authentic Movement.

Recibido: 12 de febrero de 2019 / Aceptado: 8 de junio de 2019.

Los trimestres pasaban; nosotros crecíamos: nos transformábamos, ya que, después de todo, no somos sino animales.

Virginia Woolf, Las olas

El animal es el más necesario, familiar y precioso otro del anthropos. Rosi Braidotti, Lo Posthumano

Quizás una de las prácticas humanas más notorias de la relación humano animal ha sido la antropomorfización que los primeros han ejercido sobre los segundos. De tal suerte que hemos proyectado prácticas y diseñado dispositivos para que los animales desempeñaran comportamientos que les eran ajenos como producto de la cosmovisión androcéntrica. Ted Benton

Cómo citar este artículo: FERRER ÁLVAREZ, Mireia, "Animales, teorías feministas posmodernas y prácticas artísticas", Boletín de Arte-UMA, n. ${ }^{40,}$, Departamento de Historia del Arte, Universidad de Málaga, 2019, pp. 135-146, ISSN: 0211-8483, e-ISSN: 2695-415X, DOI: http://dx.doi.org/10.24310/BoLArte.2019.v0i40.5637 
denominaba «species narcisism» (Benton, 1988: 12) al proceso de humanización de la naturaleza.

¡Dejemos de hacer del hombre la medida de todas las cosas! ¡Evaluemos las otras especies por lo que son! Estoy seguro de que descubriremos así numerosos pozos sin fondo, algunos de los cuales son todavía inimaginables para nosotros. Frans de Waal (citado en Lenoir, 2015: 26).

La concepción del hombre como medida de todas las cosas hunde sus raíces en la conformación de la mentalidad occidental del Renacimiento y desde entonces ha constituido un modelo afianzado por el pensamiento ilustrado del siglo XVIII y el positivista del siglo XIX. Harari identifica la capacidad del ser humano de aprehender y referir el mundo no existente, esto es, la mitología que este autor denomina pegamento mítico, como aquello que nos ha situado en la cúspide frente al resto de especies, «entre nosotros y los chimpancés, la verdadera diferencia reside en el pegamento mítico que une a grandes cantidades de individuos, familias y grupos. Este pegamento ha hecho de nosotros los amos de la creación» (Harari, 2015). El hombre es paradigma y modelo, el otro/a es por oposición su negativo.

A finales de los años 60 del siglo XX, sin embargo y al albur de las críticas posmodernas, comienzan a plantearse cuestionamientos que hacen tambalear los pilares que habían apuntalado las certezas de dicha cultura basada en la primacía humanística. El pensamiento post-estructuralista, fundamentado en el cuestionamiento del Yo cartesiano propio de la llustración y el racionalismo occidental, ha constituido uno de esos dinamitadores. En El animal que luego estoy si(gui)endo Jacques Derrida conforma uno de sus hilos argumentales en torno a la cuestión posthumanista y la construcción androcéntrica. Animote es un término que según Derrida define mejor una realidad mucho más compleja que no se reduce a la consabida oposición binaria hombre-animal que reduce el riquísimo universo de los seres vivos «no hay animal en singular general, separado del hombre por un solo límite indivisible. Es preciso afrontar que hay unos seres vivos cuya pluralidad no se deja reunir en una sola figura de la animalidad simplemente opuesta a la humanidad» (Derrida, 2008: 65). Así mismo, Deleuze y Guattari hablaban del proceso de devenir como fundamento ontológico del ser posmoderno, en esos procesos de traslación el ser humano deviene en otros cuerpos, otros seres, el otro negado y confrontado por el pensamiento moderno es subvertido por la necesidad de devenir en él.

Junto al pensamiento post-estructuralista y en el seno de ese marco de crítica posmoderna el feminismo como «teoría, [...] militancia social y política [...] práctica cotidiana [...] forma de entender y vivir la vida» (De Miguel, 2017: 29) ha constituido uno de los envites más severos a ese modelo androcéntrico pues nos referimos a una de las más concienzudas estrategias filosóficas deconstructivas. En 1970 comienzan a surgir las primeras voces eco-feministas ${ }^{1}$ como la de Françoise d'Eaubonne quien sostenía la similitud entre la explotación del hombre hacia la mujer, la tierra y los animales. El antropocentrismo se vinculaba a la cultura de la explotación y dominio sistémico del hombre sobre el otro/a, como planteamiento de «naturaleza-dominio». Andrée Collard, en su canónico texto, definía esta relación de agresión y devastación como una violación: "In patriarchy, nature, animals and women are objectified, hunted, invaded, colonized, owned, consumed and forced to yield and produce (or not). This violation of the integrity of wild, spontaneus Being is Rape» (Collard y Contrucci, 1989: 1)².

Esta vinculación entre la explotación del hombre hacia la alteridad se hallaba ya, tal y como afirma Alicia Puleo, en las teóricas de la primera ola del feminismo: Olimpia de Gonges o Mary Wollstonecraft. Estas autoras esgrimieron sus reservas ante el trato del hombre hacia los animales, un maltrato que Wollstonecraft equiparaba a «la tiranía sobre esposas, hijos y servidores» (Puleo, 2011: 362).

Al ecofeminsimo se unieron posteriormente las teorías posthumanistas de los años 90. En cierta medida mientras el Ecofeminismo denunciaba y atacaba las consecuencias de las políticas de progreso que las sociedades postindustriales habían engendrado, el posthumanismo atacaba las estructuras de las que emanaban dichas políticas androcéntricas. Autoras como Donna Haraway o Rosi Braidotti concebían que la crítica a la primacía del hombre como especie entre otras especies y el desarrollo tecnológico, que hacía posible otras formas de vida, debían hacernos revisar los parámetros del humanismo. En esa revisión debían, así mismo, ponerse en cuestión las relaciones del binarismo dualista que había caracterizado al pensamiento moderno occidental: hombre/mujer, cultura/naturaleza, humano/animal o humano/máquina. 


\section{Artificial-natural}

El arte, sin duda, es una de esas prácticas, a las que nos referíamos en párrafos anteriores, que los humanos hemos proyectado en el otro/animal. Forman parte de la mitología historiográfica, los ejemplos de Hokusai y su idea del gallo con las patas impregnadas de pigmento rojo dejando sus huellas en el papel, en una suerte de expresionismo abstracto avant la lettre o el burro Aliboron quien se constituyó como ejemplo de una de las primeras boutades en torno a las manifestaciones artísticas modernas (Ferrer, 2007: 541543)33. Por más que tras estas anécdotas, aun acometidas por animales a los que se les presupone una capacidad, se advierta la presencia de la concepción humana.

Entendemos por artificial todo objeto, práctica o manifestación en el que reside la intervención humana ${ }^{4}$. La convención cultural que es arbitraria y aprendida establece que el arte solo puede ser artificial y por tanto contrario a lo natural, en ese sentido la cultura occidental sustenta el sentido binario proveniente de la llustración entre cultura y naturaleza, lo natural no puede ser artístico por oposición a lo artificial que sí lo es.

Bajo esa premisa se articulan los criterios de la ontología del arte, lo cual no implica que otro de los valores que conforma la categoría artística como es lo estético pueda hallarse tanto en lo artificial como en lo natural. Tal y como afirma Umberto Eco «La experiencia de la belleza, del placer estético ante una forma, se experimenta también en presencia de lo que no es arte: frente a una montaña, una pradera, una puesta de sol» (Eco, 1978: 188). Lo natural puede ser estético.

La oposición artificial/natural, no se muestra tan evidente en otras culturas, a ese respecto algunas filosofías orientales son un claro ejemplo como se deduce de la consideración hacia los shintai5. Sumi de Narita Katsuhiko 1969 se manifiesta como una obra claramente reveladora ya que conculca esa dualidad cultura-naturaleza que la cultura occidental mantiene. En esta obra el autor prendía fuego a varios bloques de carbón dejando que la naturaleza creara sus propias formas y produjera la escultura, convirtiendo lo natural en artificial. Como afirmaba John Berger «El arte no imita la naturaleza; imita a una creación, unas veces para proponer un mundo alternativo, otras sencillamente para ampliar, confirmar, hacer social, la breve esperanza que ofrece la naturaleza. El arte es una respuesta organizada a aquello que la naturaleza nos deja entrever ocasionalmente» (Berger, 1990: 22).

Estas creencias de la unicidad artificial/natural fueron impregnando el arte occidental posmoderno, estableciendo un diálogo cada vez más próximo con lo natural. El sentido orgánico del arte como reflejo del comportamiento de la naturaleza se halla en numerosas propuestas de finales de los años 60 y en la década de los 70, que transitan por el Land Art, el Body Art o el Arte Povera.

En el seno de esa misma concepción dualista se sitúa la relación humano-animal. El animal es por oposición al hombre, de la misma manera que lo natural lo es a lo artificial.

\section{Humano-animal}

Nuestra relación con los animales es un espejo que nos muestra en qué nos hemos convertido con el paso de los tiempos. En el espejo no solo aparecen los horrores cometidos por nuestra especie al explotar a otros seres sensibles, sino el rostro macilento de una humanidad que está perdiendo su alma (Pelluchon, 2018: 1).

En 1971 la artista Bonnie Ora Sherk (1945, Massachusetts), cuyas piezas habían estado caracterizadas por la preocupación medio ambiental y por la fenomenología experiencial, realiza Public Lunch [1]. En esta performance el público que acudía al zoo se encontraba con el extrañamiento de hallar a una mujer, Sherk, comiendo un almuerzo en una jaula contigua a la de leones y tigres. Junto a Sherk había otra pequeña jaula en la que jugueteaba un ratón. Mientras los felinos devoraban sus piezas de carne cruda, Sherk degustaba una suculenta comida encargada a uno de los restaurantes más lujosos de San Francisco.

Lunch was a seminal piece for me. During the course of the Performance, I paced, ate my human meal, climbed up the ladder to the platform above, wrote what I was thinking and feeling (on Waldorf Astoria stationery), lay down, and rested. As I was lying down, gazing through the beautiful skylight above, viewing the clouds and birds flying overhead, the tiger in the adjacent cage, got up on his haunches and peered over at me. I thought, «This tiger is perceiving me; he is looking at 


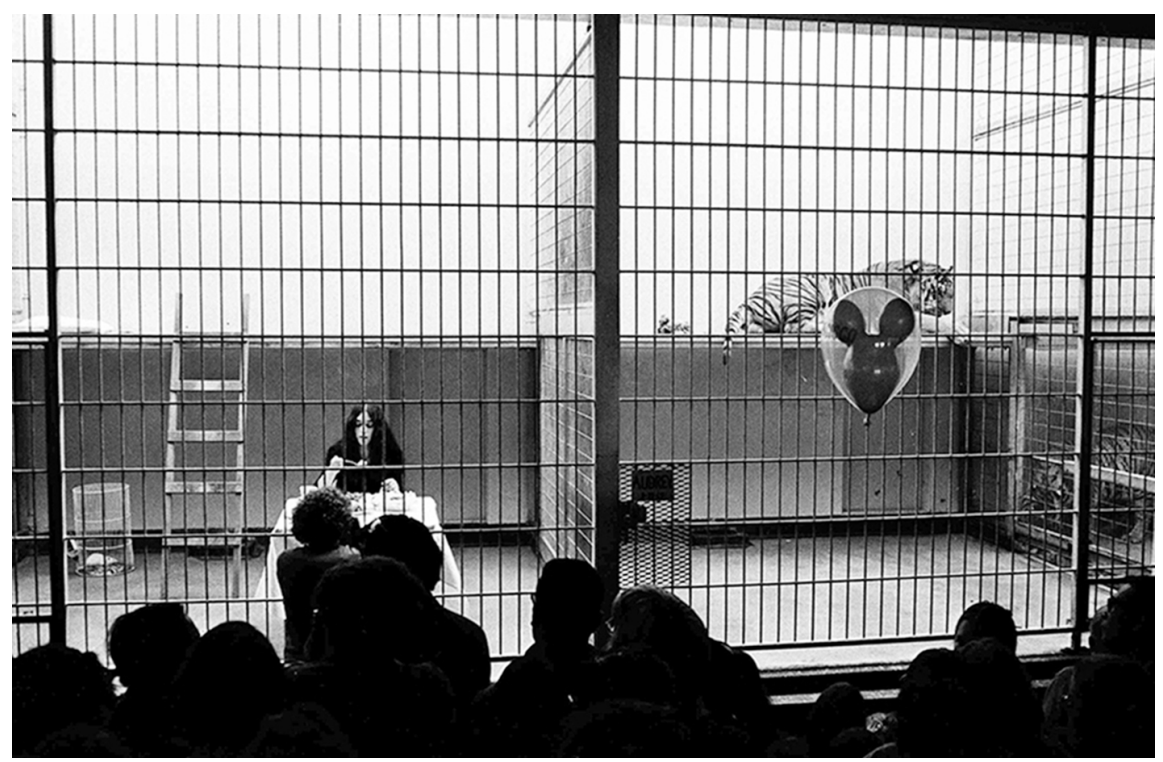

1. Bonnie Ora Sherk. Public Lunch (Almuerzo público). Acción performativa. San Francisco,1971. (C) Bonnie Ora Sherk

me. What is he seeing? What is he thinking? What is he feeling?» (Smith, 2013: 129) ${ }^{6}$.

Al situar al animal en un mismo ámbito espacial que el del humano la artista estaba forzándonos, también, a otorgarles la capacidad de sentir y pensar "the animals were performers, as was I. But we were also beings in our own right» (Smith, 2013: 130), "Los animales eran ejecutantes, como yo. Pero nosotros (humanos) éramos seres por derecho propio», en un claro proceso de deconstrucción del dualismo racionalista.

En cierta medida la reflexión de Sherk se aproxima a la incerteza que provoca la presencia del otro frente a frente pues tal y como Derrida planteaba:

Ante el gato que me mira desnudo, ¿tendría yo vergüenza como un animal que ya no tiene sentido de su desnudez? ¿O, al contrario, tendría vergüenza como un hombre que conserva el sentido de la desnudez? ¿Quién soy yo entonces? ¿Qué soy? ¿A quién preguntarle sino al otro? ¿Quizás al propio gato? (Derrida, 2008: 19-20)

Pero también con ello y tal y como opina Cortés Zulueta, Sherk, estaba contribuyendo a generar «una reflexión acerca de los aspectos que compartirían mujeres y animales como objetos sometidos a la mirada y al dominio del hombre, que sería quien los encierra y los observa, literal o metafóricamente» (Cortés, 2015: 185). Efectivamente, el giro visual, como esgrime Luce Irigay (Pollock, 2013:11), solo es entendido desde la objetivación que realiza la visión masculina, es la mirada escoptofílica de la que habla Laura Mulvey (Mulvey, 1988) que objetiviza y sexualiza al cuerpo observado, normalmente el de una mujer. El cuestionamiento de esta pieza opera en el ámbito de la sexualización del sujeto/objeto, o lo que es lo mismo, la cultura androcéntrica del hombre entendido como sujeto racional con autoridad y capacidad discursiva y la mujer/animal irracional y sensible objeto de contemplación. En ese sentido unos años después Donna Haraway articula la disolución del binarismo de un sujeto que conoce y un objeto por conocer para hablar de actores y actantes. El actor conoce en un diálogo al actante que adquiere un papel activo en el proceso de conocimiento. "Si el mundo existe para nosotros como naturaleza, esto designa un tipo de relación, una proeza de muchos actores, no todos humanos, no todos orgánicos, no todos tecnológicos» (Haraway, 1999: 123).

Así mismo, Public Lunch entroncaba con la polémica que algunas teóricas del Ecofeminismo habían planteado 


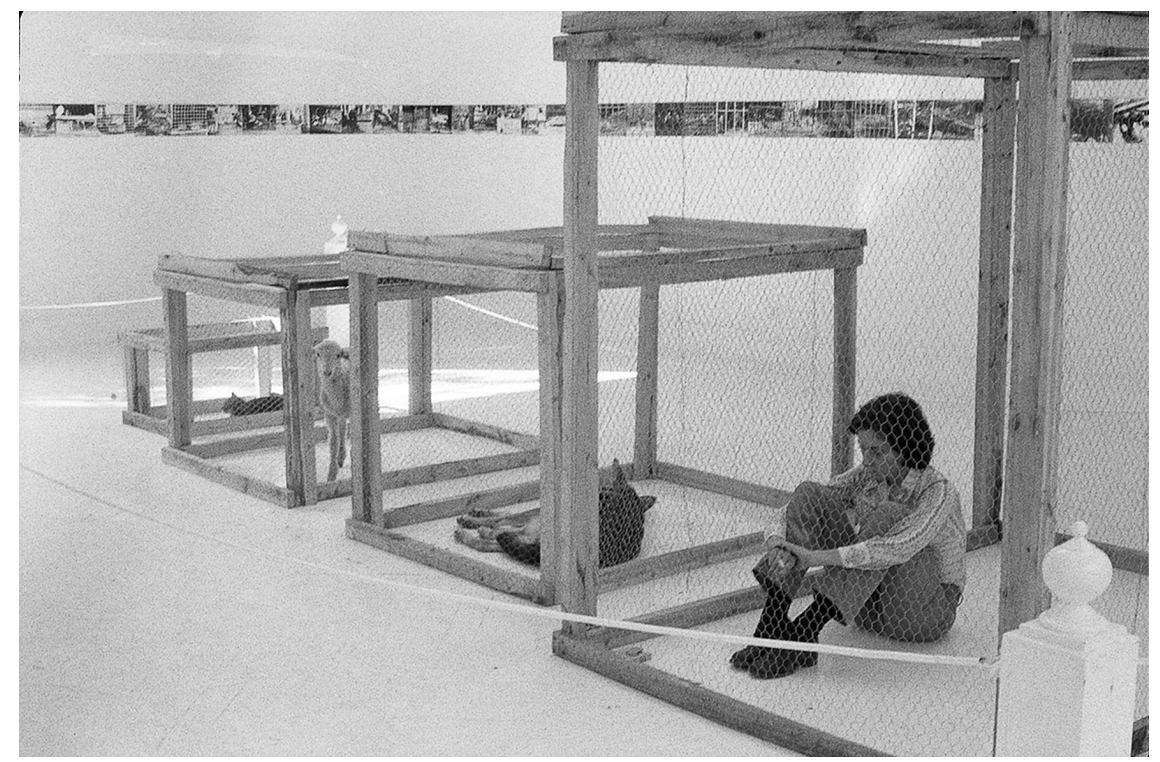

2. Fina Miralles. Imatges del zoo (Imágenes del zo0). Instalación-Acción performativa. Barcelona,1974. (C) Fina Miralles-Museu d'Art de Sabadell

con los activistas de la Liberación Animal. Para este movimiento (liderado por Peter Singer y Tom Reagan) era necesario otorgar derechos y estatuto jurídico a los animales, pues algunos poseían conciencia de sí. Según algunas ecofeministas este planteamiento reducía el ámbito de reconocimiento a la condición de racionalidad y no a lo emocional, al excluir la capacidad de sentir de los animales como elemento de consideración se estaba promoviendo la razón frente a la emoción, planteamientos, estos, que se amparaban nuevamente en la razón humana como fundamento epistemológico. De ahí que la reflexión de Bonnie Sherk: «What is he seeing? What is he thinking? What is he feeling?» (Smith, 2013: 129)7 adquiera todo su sentido en el marco de los debates sobre la condición y relación con los animales.

Solo unos años después, en 1974, la artista catalana Fina Miralles (1950, Sabadell), realizaba una acción en la Sala Vinçon de Barcelona, que llevaba por título Imatges del zoo (Imágenes del zoo) [2]. Por aquellos años se había desarrollado en Barcelona un grupo de artistas conceptuales y performativos auspiciados por iniciativas como los encuentros de Bañoles (1972), en los que se debatió e investigó sobre las nuevas corrientes del Conceptual y la Performance y por el apoyo de críticos como Alexandre Cirici, entre otros. Una de las artistas más activas en ese ámbito fue Fina Mi- ralles quien quiso evidenciar en sus obras «el vínculo entre el cuerpo y los elementos naturales, el cuerpo concebido como ser natural» (Parcerisas, 2007: 81). Imatges del zoo (imágenes del zoo) era una pieza que combinaba documentos fotográficos de parques zoológicos en la pared de la sala con una instalación-acción en el centro de la misma en la que se disponían cinco jaulas en orden creciente por tamaño albergando a una serie de animales que no solemos ver enjaulados como: una rana, un gato, un cordero, un perro y por último a la propia Fina que accionaba junto al resto de animales en el horario comercial de la galería durante los tres días que permaneció la pieza.

Con esta pieza tal y como ha referido la propia autora pretendía indagar en las constricciones que atenazan a todos estos seres, pero, así mismo, realizar una reflexión sobre las coacciones que se establecen en el desarrollo humano desde la infancia, esto es, en la propia institución familiar. No en vano, la primera intención de Miralles fue la de incluir a un niño/a en la pieza en su lugar, idea que desestimó ante las prohibiciones de la censura franquista.

Entenc un zoo com la manipulació de l'ésser humà sobre els animals. Però llavors em vaig adonar, a partir de les imatges del zoo, que com a ésser social [...] aquesta persona, nen $\mathrm{i}$ 
nena, també ha estat manipulat per tota una estructura sencera, la de la família, la de la pàtria potestat. Quin poder més enorme tenen els pares sobre les criatures! Hi ha una idealització de la infantesa que moltes vegades no és veritat. La infantesa no és idíllica, també és molt dura [...] T'adones que tot això és al més profund de la nostra societat, i per a mi això és política. No la dels partits, sinó la de les relacions humanes des dels fonaments de la família (Serra, 2018) ${ }^{8}$.

En palabras de Maite Garbayo en las obras de Fina Miralles hallamos siempre: «una voluntad de abordar las posibilidades de juego y resistencia que se esconden en el interior de un espacio fuertemente controlado" (Garbayo, 2016: 218). Sea este el del cuerpo femenino, el cuerpo del animal, el cuerpo del ser humano o instituciones como la infancia; y con ella la educación o el zoológico. Sin duda, dos instituciones, estas últimas, en los que la cultura ilustrada puso especial énfasis como campo de racionalización, control y dominio.

Otro de los binomios sometido a crítica por parte del pensamiento feminista de los años 70 fue el de mujer/naturaleza. En ese sentido, la resignificación de la relación mujer-tierra-fertilidad, piedra angular del constructo de género, estuvo en el punto de mira de numerosas prácticas artísticas. Ejemplo de ello son las obras de Ana Mendieta Silueta (1973-1977); Birgit Jurgenssen Untitled (1979); Fina Miralles Translaciones. Mujer-árbol (1973), o Mary Beth Edelson Strong medecine (1973). En esta última pieza Edelson deviene concha marina, en esa recurrencia de la formalidad vulvar y ondular que remite a la simbología del órgano reproductivo femenino, que se manifiesta también, por esas fechas, en la plástica de Judy Chicago, entre otras. Según apuntaba Lucy Lippard:

Much recent feminist art seems aimed at returning the artist back to the earth [...] many of this works resemble or specifically include ritual, which began as animal communication and persisted as magic [...] the goal is continuity [...] the primitive connection with the substance of life, or prima materia (Lippard, 1977: 32) ${ }^{9}$.

El feminismo esencialista de los años 70 ensalzaba los valores distintivos de lo femenino, Lippard abogaba por rescatar territorios estrictamente femeninos como las artes menores, la maternidad, la autobiografía. Linda Alcoff, por su parte, planteaba que esa resignificación implicaba que la pasividad de la mujer fuera interpretada como sosiego, el carácter emocional en inclinación a la crianza; la subjetividad en capacidad para la introspección y tendencia a la reflexión.

En ese sentido la animalidad ha sido otro de los estigmas de la construcción de la mujer en el imaginario colectivo, hasta el extremo que todavía hoy pervive en las capas freáticas de la cultura occidental el ideario y marchamo misógino mujer-animal. «La mujer [...] Debe causar horror / La mujer tiene hambre, y quiere comer; sed y quiere beber / Está en celo y quiere ser satisfecha / ¡Qué gran mérito! / La mujer es natural, es decir, abominable» (Baudelaire, 2009: 8).

Si bien la antropomorfización del animal es vista en nuestra cultura occidental como algo positivo ya que otorgamos un inmenso valor a animales que denotan actitudes humanas, como puede observarse en los ejemplos de gorilas que pitan o loros que hablan; la animalidad, por el contrario, se inviste de un valor completamente opuesto y negativo si la relación se establece hacia colectivos minoritarios, marginados o no normativos. Así y tal como plantea Alicia Puleo es frecuente la comparación entre homosexualidad y zoofilia cuando la finalidad es desacreditar la primera. «La animalización se ha cernido siempre como una amenaza y una condena sobre mujeres, pueblos sometidos, extranjeros, clases desfavorecidas, indígenas y minorías sexuales» (Puleo, 2011: 367).

Contrariamente a este sentido peyorativo que denigra la animalidad, la mayoría de sociedades indígenas integran en su imaginario colectivo el ritual del arquetipo del animal, suerte de proceso inconsciente y catárquico de iniciación del joven a adulto. En este sentido y a diferencia de lo que sucede en las sociedades occidentales racionalistas, la naturalización del hombre, es vista como uno de los procesos más positivos del desarrollo humano, vía de crecimiento, maduración y afirmación del sujeto, rito de paso a los que se refería también Victor Turner (2008).

Estos procesos de creación del imaginario colectivo mediante la utilización arquetípica y simbólica están en la base también del pensamiento psicoanalista de Carl Jung, según el cual todo "proceso simbólico es un vivenciar en imagen y de la imagen" (2003: 45). En ese sentido los humanos nos proyectamos en figuras animales como vehículo para la introspección y producción de imágenes, fantasmata. 


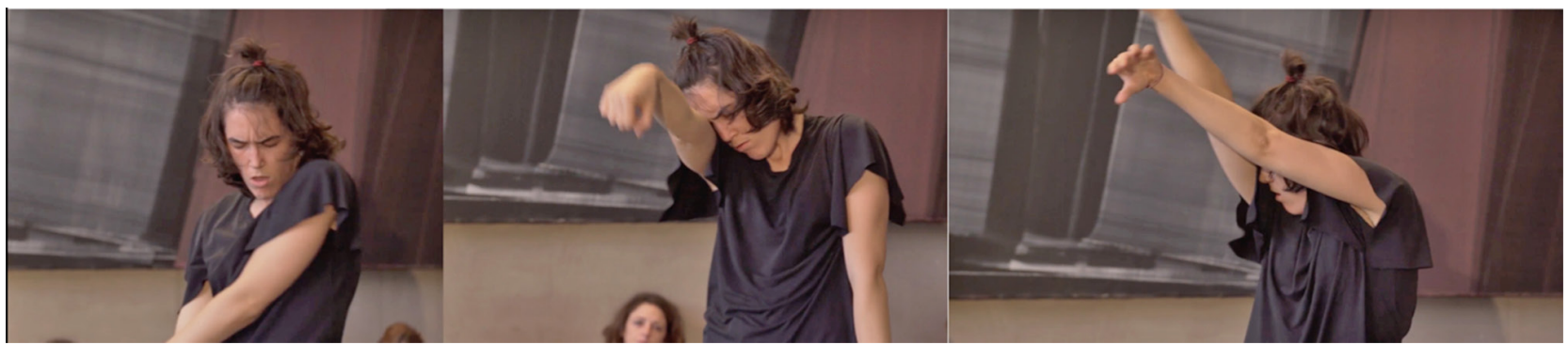

3. Oihana Altube. Práctica performativa de Movimiento Auténtico. Ciclo Radicantes. IVAM, Valencia, 2017. @ Oihana Altube-IVAM (Instituto Valenciano de Arte Moderno)

El Movimiento Auténtico constituye una práctica terapéutica, pero con un trasfondo en el ámbito de las artes vivas, fundamentalmente en la Performance y la Danza Contemporánea. No en vano, su creadora fue la coreógrafa Mary Whitehouse quien a finales de los años 60 y partiendo de las teorías de los arquetipos de Carl Jung conformó una práctica que aspiraba a liberar el cuerpo a través de la expresión corporal de imágenes y formas que provenían del inconsciente, procurando gracias a ello la transformación personal. No deja de ser sintomático que la aparición del Movimiento Auténtico corriera paralela a la práctica performativa de algunas mujeres artistas que recuperaban y resignificaban los procesos catárquicos, chamánicos y el ritual, como refería Lippard en párrafos más arriba.

En las prácticas de Movimiento Auténtico [3] (Oihana Altube, Irún, 1983) es recurrente la proyección de imágenes animales en la corporalidad del ejecutante, en un doble juego de proyección tanto por parte del público, al que se denomina testigo, que cree ver, como del que está en movimiento que ve en su interior. El Movimiento Auténtico parece devolvernos ese ser y estar (Derrida) natural y por ello constituye un excelente ejemplo para apreciar la potencialidad de los comportamientos y prácticas humanas, pero, así mismo y fundamentalmente, al entenderse como una práctica de libre expresión corporal frente al coercitivo movimiento racionalizado humano, la similitud con el gesto y el impulso animal se hace patente.

Otro ejemplo en el que podemos observar la plasmación de la animalidad es la pieza La bestia (2005) [4] de María Llopis (Castellón, 1975). Nos referimos a un video performance en el que la artista se apropia del ideario patriarcal y androcéntrico para conformar otros valores:
Jadea, gruñe, hace gestos amenazantes, escupe e incluso trepa a un árbol. De repente, parece despertar de su estado de inconsciencia, se ruboriza por verse en tal situación y vuelve a adoptar una actitud civilizada, comedida y correcta. Tanto el comportamiento recatado como el bestial están escenificados por la artista: artificial versus natural, civilizado versus animal, disciplinado versus espontáneo. Nos podemos llegar a plantear cómo de igualmente construidas y estereotipadas están las actitudes disciplinadas y las subversivas (Llopis, 2005).

La bestia y el soberano corresponde al título de uno de los seminarios impartidos por Jacques Derrida entre 2001 y 2003, fecha de su muerte, en la Universidad de la Sorbon-

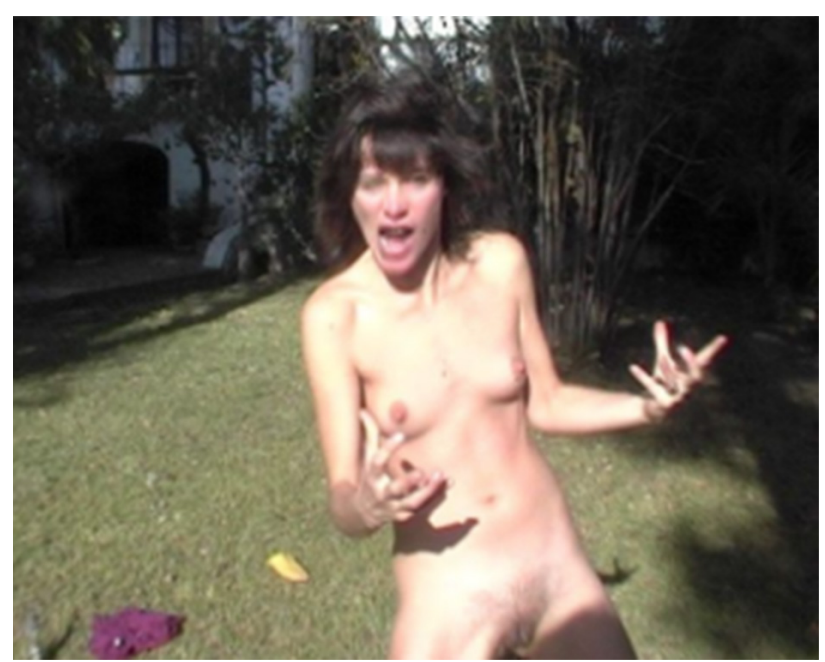

4. María Llopis. La bestia. Video-performance, 00:02:16, Valencia, 2005. (C) María Llopis 


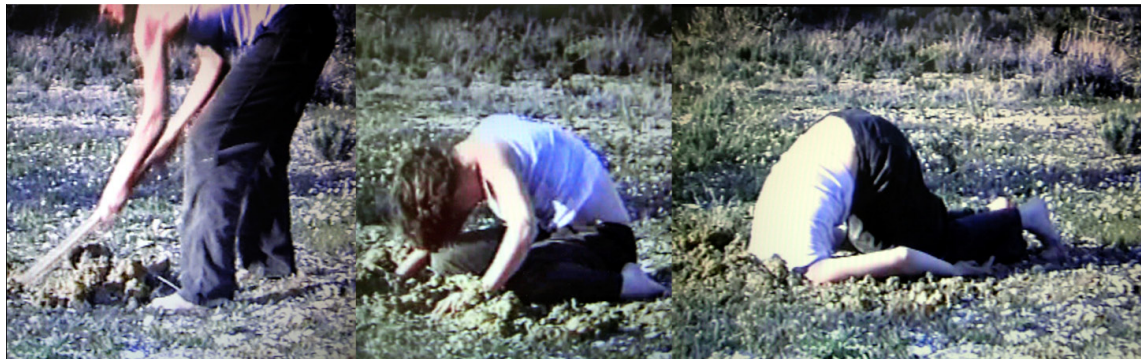

5. Olga Diego. Avestruz.

Video-performance,

00:05:52:07, Sierra de

Aitana, Benifato, Alicante,

2001. (c) Olga Diego ne de Paris. En estos cursos el autor, entre otros muchos asuntos, analizaba los procesos en los que «el» soberano, y remarcaba el artículo masculino de este sustantivo como condición de dominio de la sociedad patriarcal, deviene bestia, y en los que «la» bestia, entendida como el otro femenino deviene soberano; con ello Derrida cuestionaba los límites que nos definen y las prácticas asignadas como campos difusos «La bestia es el soberano que es la bestia, compartiendo ambos un estar fuera-de-la-ley, por encima o a distancia de las leyes» (Derrida, 2010: 36). Lo político sería el ámbito contractual al que se someten los hombres, la bestia y el soberano estarían por debajo y por encima respectivamente. La mujer de la pieza de María Llopis se somete al pacto contractual que le es ajeno y se disciplina, la bestia actúa fuera del discurso, tanto en uno como en otro caso, el discurso siempre lo enuncia el otro.

Sin duda, una de las referencias más notables hacia el universo animal se halla en la obra de la artista alicantina Olga Diego (Alicante, 1970). En 2001 realiza la pieza Avestruz [5] un video performance en la Sierra de Aitana de la localidad alicantina de Benifato. En palabras de la autora una:

Reflexión sobre el miedo. Representar la angustia y dificultad para salir de un proceso de ansiedad y las situaciones de pánico que lo acompañan. Expresión performativa reflejo de las experiencias de las personas capturadas por el miedo en una locura y lucha desmedida. Una acción que imita al avestruz en la frase: «esconder la cabeza como los avestruces». Esconder inútilmente la cabeza bajo tierra dejando el resto del cuerpo a la intemperie y desprotegido. Como reflejo de aquel miedo que no podemos identificar y por tanto, ante el que tampoco sabemos con qué herramientas luchar. Solo acertamos a pensar y desear desaparecer de la faz de la tierra. Buscamos el lugar que nos elimina y nos acoge. Ese lugar donde escondernos y en el que obtener cobijo y protección, porque con no ver, queremos creer que no existe (Diego, 2001).

La acción entrañaba un excesivo riesgo físico, no en vano, la artista experimentó un proceso de asfixia real ante la imposibilidad de sacar su cabeza sepultada en la tierra. La performance de Olga Diego enlazaba con la tradición performativa de los años 70 de autores como Marina Abramovich, Chris Burden, Vito Aconcci o Gina Pane, entre otros, prácticas a la que Kathy O'Dell denominaba «trabajos masoquistas» (O'Dell, 1988), en ellas el cuerpo deviene discurso inmolatorio, cuerpos precipitados al abismo del arte por el arte (Ferrer, 2018: 121).

Podemos observar en estas dos obras, tanto en la de Llopis como en la de Diego, la subversión de los constructos dualistas propios de la modernidad: cultura/naturaleza, humano/animal, si el ser humano ha atropomorfizado al animal, el proceso inverso radica en animalizar al antrophos.

Se plantean en estas acciones varias cuestiones que refieren la descomposición del sujeto que se adviene con la posmodernidad. Sujetos desdibujados que devienen otredad. Exploraciones de lo inestable, lo híbrido, propuestas que entroncan con los planteamientos post-estructuralistas de autoras como Butler, para quien la identidad posmoderna no es sino una puesta en escena y una ficción «La reconceptualización de la identidad [...] producida o generada, abre posibilidades de "capacidad de acción"» (Butler, 1990: 177).

Esa premisa de la traslación y el cambio está, asimismo, en los planteamientos de Gilles Deleuze y Félix Guattari. La metáfora kafkiana de la metamorfosis se constituye como un modelo referencial en el proceso de definición o transmutación del individuo posmoderno. Devenir es para estos autores una promesa de libertad, no se trata de un proceso imitativo sino performativo, en el que devenir otro se 


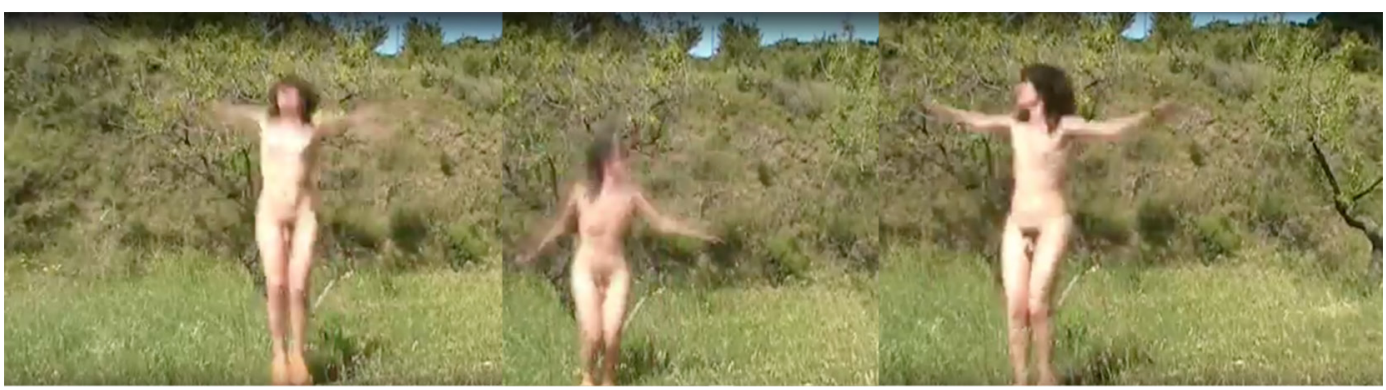

6. Olga Diego. Flying Frog. Video-performance. () Olga Diego

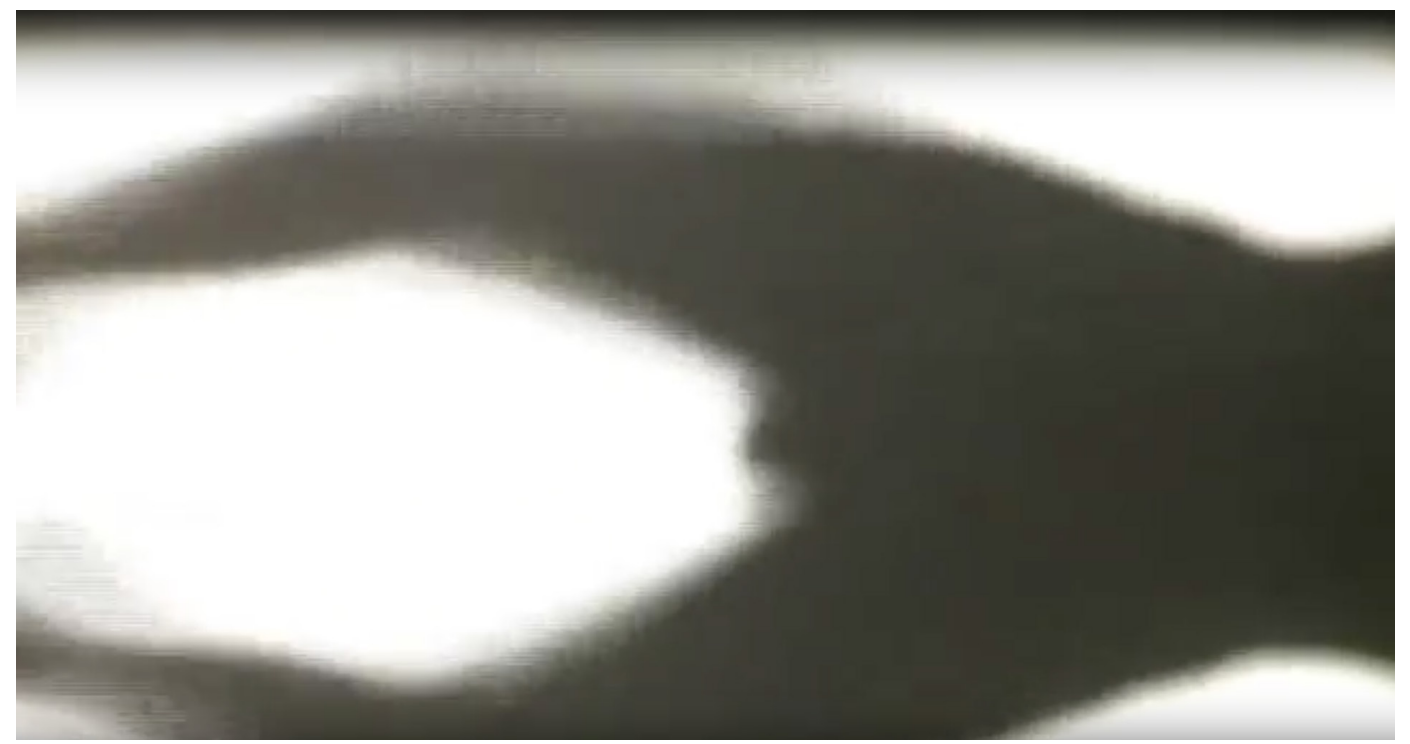

7. Olga Diego. Video-performance. @ Olga Diego

convierte en una manera de escapar de los rígidos modelos culturales. Un devenir que retoma Rosi Braidotti al apelar al proceso de devenir animal, devenir máquina, devenir tierra. Porque como opina Estrella de Diego «Los cuerpos fuera de las estructuras de poder a veces dan sorpresas, asombran, confunden, se desplazan con sus disfraces y desplazan la mirada, los cuerpos nunca son para siempre» (De Diego, 2005: 186).

En la pieza No yo Olga Diego transmuta en diferentes géneros y cuerpos, mediante la utilización de un pene postizo, prótesis que como opina Beatriz Preciado, siguiendo a Deleuze y Guattari, conforma el sexo: «No nos falta nada [...] ni el pene, ni los senos. El cuerpo es ya un territorio por el que cruzan órganos múltiples e identidades diversas» (Pre- ciado, 2002: 167-168). En Flying Frog [6] y [7] este mismo personaje de género nomade (Braidotti), que Diego ha conformado, deviene pájaro, aleteando de manera torpe y obsesiva con la intención de volar pues el vuelo conforma otro de los más ricos imaginarios de la obra de Diego. En otra acción el personaje realiza gestos compulsivos que reproducen el movimiento de una rana.

Un devenir no es una correspondencia de relaciones. Pero tampoco es una semejanza, una imitación y, en última instancia, una identificación [...] El devenir no produce otra cosa que sí mismo [...] lo que es real es el propio devenir [...] El devenir-animal del hombre es real, sin que sea real el animal que él deviene (Deleuze y Guattari, 2008: 244). 

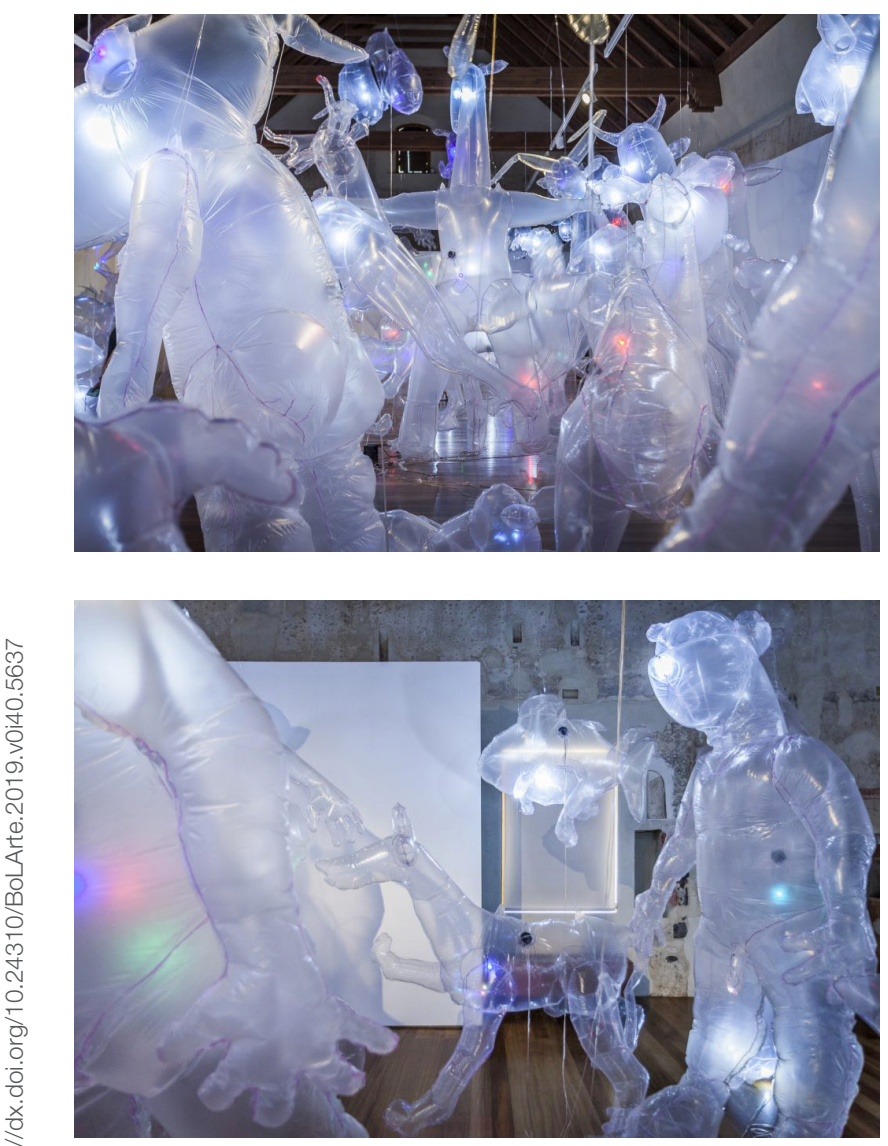

8 y 9. Olga Diego. Jardín autómata. Esculturas de aire dotadas de movimiento y respiración. Piel plástica (polietileno baja densidad) termosellado y texturado, circuitos electrónicos y programación. 2018.

(C) Olga Diego-Consorcio de Museos de Generalitat Valenciana

Dicho al modo de Deleuze y Guattari, Olga Diego no se convierte en rana, tampoco imita a una rana, como tampoco imita a un hombre por el hecho de incorporarse un pene postizo a su cuerpo, deviene rana, deviene hombre, en un proceso de cambio y metamorfosis que no tiene estadio o ciclo final. Pues el estadio posterior al de la metamorfosis es el preludio de otro devenir. Como opina Haraway «las metáforas son tropos y herramientas» (Haraway, 1995: 86).

Jardín Autómata (2018) [8] y [9] es una instalación en la que Olga Diego proyecta todo su imaginario animal. Se trata de una recreación del Paraíso del Tríptico del Jardín de las Delicias del Bosco, realizada con esculturas en plástico y dispositivos electrónicos que actúan insuflando aire a las esculturas en un ritmo continuo de llenado y vaciado. Un universo armónico de:

Hombres y animales, pero también homúnculos, humanoides y seres híbridos: Delfines tiburones, huevos y peces con piernas, criaturas híbridas de varios sexos, humanoides de inmensos pechos y antenas, perros de dos cabezas, seres cabeza globo, fresas-humano con tentáculos y apéndices. Seres esquivos a la taxonomía biológica, a ese espejismo ilustrado por clasificar y compartimentar el mundo (Ferrer, 2018: 5).

Los animales de Jardín Autómata son los actantes a los que se refería Donna Haraway «Los objetos no existen antes de ser creados, son proyectos de frontera [...] implantar (y ver) fronteras es una práctica arriesgada» (Haraway, 1995: 345).

Cuerpos frontera que se materializan en cuerpos de enormes extremidades y órganos genitales, cuerpos duales, son los cuerpos sin órganos a los que apela Deleuze y Guattari y en los que se observa la capacidad para «liberarnos de los puntos de subjetivación que nos fijan que nos clavan a la realidad dominante» (Deleuze y Guattari, 2008: 159)

Queremos cerrar este artículo en el que hemos querido ilustrar cómo el feminismo y las prácticas artísticas en las que se proyectan estas teorías, han contribuido al cuestionamiento de la hegemonía de las especies, a la crítica a la jerarquía de los sexos y a la fractura de los dualismos que conllevan la concepción del mundo en un yo y un otro/os/ as que no son sino por oposición a la categoría normativa; con una cita de Rosi Braidotti en la que se vislumbra un nuevo porvenir.

Yo me quedo de este lado: del lado de lo que ya no se identifica con las categorías dominantes del sujeto, pero que no es aún del todo libre de las jaulas de la identidad, o sea, del lado de lo que es diferente y sigue diferenciándose de sí y, por ende, está cerca de zoe, el sujeto postantropocéntrico. Para mí, estos elementos rebeldes están conectados a la conciencia feminista de qué significa encarnar un cuerpo de mujer. (2015: 98) 


\section{Notas}

1 El eco-feminsimo ha presentado diferentes posicionamientos a lo largo de su evolución pudiéndose hablar de un eco-feminismo esencialista en el caso de François d'Eubonne, espiritualista SHIVA, Vandana (1995), Abrazar la vida. Mujer, ecología y supervivencia, Horas y horas, D.L., Madrid, 1995; ilustrado PULEO, Alicia H. (2011), Ecofeminismo para otro mundo posible, Catedra, Madrid, o ético WARREN, Karen J. (2003), Filosofías ecofeministas. Icaria, Barcelona (Tardon, 2011: 534)

2 En el patriarcado, la naturaleza, los animales y las mujeres son objetivados, cazados, invadidos, colonizados, poseídos, consumidos y obligados a ceder y producir (o no). Esta vulneración de la integridad del ser salvaje, espontáneo, es una violación. Todas las notas de este artículo en otros idiomas distintos al castellano han sido traducidas por la autora.

3 En 1910 el dueño del café parisino Le lapin agile junto a un grupo de artistas y al periodista Roland Dorgelès presentan a la Exposición del Salon de los Independientes de Paris el cuadro Puesta de sol en el Adriático realizada por Joachim-Rapphaël Boronali creador de un nuevo movimiento artístico que denominaron "excesivismo". El autor real no era otro que el burro de la taberna que con un pincel atado a la cola había realizado un lienzo de brochazos gruesos y abstractos que llegó incluso a recibir alguna crítica artística. El propósito de esta «performance» era poner en cuestión el carácter del Salon de los Independientes de Paris creado en 1884 sin premios ni jurados como respuesta a la parcialidad de los jurados del Salon des Beaux Arts. Pero, así mismo, se realizaba una mofa a las nuevas tendencias artísticas como el fauvismo y el expresionsimo. Dos años después en Rusia Mijail Larionov y Natalia Goncharova crearon el grupo denominado La queue de l'âne en honor a este suceso.

4 RAE. Del lat. artificiâlis. 1. adj. Hecho por mano o arte del hombre.; 2. adj. No natural, falso; 3. adj. Producido por el ingenio humano.; 4. adj. Disimulado, cauteloso. En: <https://dle.rae.es/?id=3rMOtTc> (fecha de consulta: 28/01/2019).

5 En la religión sintoísta se denomina shintai a los objetos físicos en el interior o cercanos a los santuarios a los que se considera repositorios de los espíritus que moran. Los shintai más comunes son objetos manufacturados como espejos, joyas o esculturas, sin embargo, también pueden ser objetos naturales como rocas, montañas, árboles y cascadas.

6 El Almuerzo fue una pieza fundamental para mí. Durante el curso de la Performance, caminé, ingerí mi comida humana, subí la escalera a la plataforma superior, escribí lo que estaba pensando y sintiendo (en la libreta del Waldorf Astoria), me acosté y descansé. Mientras estaba acostada, mirando a través de la hermosa claraboya de arriba, las nubes y los pájaros volando por encima, el tigre en la jaula adyacente, se levantó en cuclillas y me miró. Pensé: «Este tigre me está percibiendo; me está mirando ¿Qué está viendo? ¿En qué está pensando? ¿Qué está sintiendo él?».

7 «Qué está viendo? ¿En qué está pensando? ¿Qué está sintiendo él?».

8 Entiendo un zoo como una manipulación del ser humano sobre los animales. Pero entonces me di cuenta, a partir de las imágenes del zoo, que como ser social esta persona, niño o niña, también ha sido manipulado por toda una estructura entera, la de la familia, la de la patria potestad. ¡Qué poder más enorme tienen los padres sobre las criaturas! Existe una idealización de la infancia que muchas veces no es verdad. La infancia no es idílica, también es muy dura [...] Te das cuenta que todo esto está en lo más profundo de nuestra sociedad y para mí eso es política. No la de los partidos, sino al de las relaciones humanas desde los fundamentos de la familia.

9 El arte feminista más reciente parece tener como objetivo devolver al artista a la tierra [...] muchas de estas obras se parecen o incluyen específicamente el ritual, que comenzó como comunicación animal y persistió como magia [...] el objetivo es la continuidad [...] la conexión primitiva con la sustancia de la vida, o prima materia.

\section{Bibliografía}

BAUDELAIRE, Charles (2009), Mi corazón al desnudo (traducción Jorge Segovia), Maldoror Ediciones, Vigo.

BENTON, Ted (1988), «Humanism = Speciesism? Marx on Humans and Animals», Radical Philosophy, n. ${ }^{\circ}$ 50, pp. 4-18.

BERGER, John (1990), El sentido de la vista, Alianza, Madrid.

BRAIDOTTI, Rosi (2012), Metamorfosis. Hacia una teoría materialista del devenir, Akal, Madrid.

- (2015), Lo posthumano, Gedisa, Barcelona.

BUTLER, Judtih (1990), El género en disputa, Paidós, Barcelona.

COLLARD, Andrée y CONTRUCCI, Joyce (1989), Rape of the Wild: Man's Violence Against Animals and the Earth, Indiana University Press, Indiana.

CORTÉS ZULUETA, Concepción (2015), Fundamentos biológicos de la creación: Animales en el arte y arte animal, Universidad Autónoma de Madrid, Madrid.

DE DIEGO, Estrella (2005), Travesías por la incertidumbre, Seix Barral, Madrid.

DE MIGUEL, Ana (2015), Neoliberalismo sexual. El mito de la libre elección, Cátedra-Universitat de València, Madrid.

DELEUZE, Gilles y GUATTARI, Félix (2008), Mil mesetas, Pretextos, Valencia.

DERRIDA, Jacques (2008), El animal que luego estoy si(gui)endo, Trotta, Madrid.

- (2010), Seminario. La bestia y el soberano, vol. I. Manantial, Buenos Aires.

DIEGO, Olga, «Avestruz», En: <http://olgadiego.blogspot.com> (fecha de consulta: 23-01-2019). 
ECO, Umberto (1978), La definición del arte, Martínez Roca, Barcelona.

FERRER, Mireia (2007), París y los pintores valencianos 1880-1914, Tesis Doctoral, Valencia, Servei de Publicacions de la Universitat de València, Valencia.

- (2018), Jardín Autómata de Olga Diego, Consorcio de Museos de la Generalitat Valenciana, Valencia.

- (2018), «Cuerpos propios. Antagonismos en el arte de performance femenina en la época del giro performativo», Asparkia. Investigació feminista, n. ${ }^{\circ} 33$, pp. 117-132.

GARBAYO, Maite (2016), Cuerpos que aparecen. Performance y feminismo en el tardofranquismo, Consonni, Bilbao.

HARARI, Yuval Noah (2015), Sapiens: de animales a dioses. Una breve historia de la humanidad, Debate, Barcelona. HARAWAY, Donna (1995), Ciencia, cyborgs y mujeres: la reinvención de la naturaleza. Cátedra, Madrid.

- (1999), «Las promesas de los monstruos: Una Política regeneradora para otros inapropiados/bles», Política y Sociedad, n. 30, Madrid, pp.121-163.

JUNG, Carl (2003), Arquetipos e inconsciente colectivo, Paidós, Barcelona.

LENOIR, Frédéric (2017), Carta abierta a los animales, Ariel, Barcelona.

LIPPARD, Lucy (1977), "Quite contrary: Body, Nature, Ritual in Women's Art», Chrysalis. A Magazine of Women's Culture, n. ${ }^{\circ} 2$, p.31-50. LLOPIS, María, «La Bestia». En: <https://www.mariallopis.com/portfolio/la-bestia/> (fecha de consulta: 22-1-2018).

MULVEY, Laura (1988), Placer visual y cine narrativo, Centro de Semiótica y Teoría del Espectáculo. Documentos de Trabajo Eutopías, Valencia. O'DELL, Kathy (1998), Contract with the skin, University of Minnesota Press, Minessota.

PARCERISAS, Pilar (2007), Conceptualismo(s) poéticos, políticos y periféricos. En torno al Arte Conceptual en España 1964-1980, Akal, Madrid.

PELLUCHON, Corine (2018), Manifiesto animalista. Politizar la causa animal, Reservoir Books, Barcelona.

POLLOCK, Griselda (2013), Visión y diferencia. Feminismo, feminidad e historias del arte, Fiordo, Buenos Aires.

PRECIADO, Beatriz (2002), Manifesto Contrasexual, Opera Prima, Madrid.

PULEO, Alicia (2011), Ecofeminsimo para otro mundo posible, Cátedra-Universitat de València, Madrid.

SERRA, Catalina, «Fina Miralles: Per viure has de tenir coratge». En: <https://www.ara.cat/suplements/diumenge/Fina-Miralles-conceptual-nacional-cultura_0_2084191775.html > (fecha de consulta: 22-1-2018).

SMITH, Stephanie (2013), Feast. Radical hospitality in Contemporary Art, Smart Museum of Art-University of Chicago, Chicago.

TARDÓN, María (2011), «Ecofeminismo. Una reivindicación de la mujer y la naturaleza», El Futuro del Pasado, n. ${ }^{\circ}$ 2, pp. $533-542$.

TURNER, Victor (2008), The ritual process: structure and anti-structure, Aldine Transaction, Chicago.

WOOLF, Virginia (2013), Las olas, Lumen, Barcelona. 